From the Association

of Family Medicine Residency Directors

Ann Fam Med 2011;9:91. doi:10.1370/afm.1218.

\section{YOU GET WHAT YOU PAY FOR, AND IT'S TIME TO STOP PAYING FOR WHAT WE'VE BEEN GETTING}

As the sonic boom of the Patient Protection and Affordable Care Act (PPACA) passed overhead, it was clearly family medicine at the wave front. As nature abhors a vacuum, now the legislative agenda has left in its wake the clean-up of implementation and regulation. With respect to Graduate Medical Education (GME), AFMRD is uniquely positioned to provide leadership for family medicine in this area.

The new 15 -member National Health Care Workforce Commission will be faced with ever-worsening ratios of primary care to specialty physicians. Immediate advocacy agenda items towards the Commission should include the methods for allocation of new Medicare GME slots and the fleshing out of recent MedPAC recommendations into reality.

Initially, a definition of primary care must be established. Ideally, all would agree with AAMC and present it to MedPAC as a fait accompli to be incorporated into all forthcoming regulatory language. The distribution of money and training slots will revolve around this point, and we can easily defend the need to be specific. A recent retrospective review' showed that almost one-half of outpatient visits to medical subspecialists were for "routine follow-up and preventive care". These visits could be more efficiently and effectively managed by family physicians. Coordination of care, a stated goal of MedPAC, would thereby be greatly improved. The study also showed that the specialists shared the care of these referred patients with other specialists in almost one-third of cases. How much of this "laterally-referred" care could have been definitively managed by a family physician-led team? Numbers reflecting this economic impact are needed to demonstrate that more family physicians would result in more efficient and less costly medical care.

Since we face a physician shortage crisis, it's crucial to show that adding more specialists to the workforce will actually worsen the crisis. There will most likely be higher expenditures per patient, particularly at the end of life, with no change in the desired outcomes (chronic disease prevention, etc.) Adding primary care manpower, in contrast, costs less and improves the outcomes MedPAC desires. It is worth pointing out that training a family physician takes less time and money.

Recommendations for how the new GME slots are distributed should be developed. Programs, hospitals, or teaching health centers that are able to demonstrate a record of producing real primary care doctors must be rewarded. The Commission should be required to use rather than merely consider this determining factor.

MedPAC has recommended that distribution of funds for the new slots should be done after consulting with health care organizations, patients, and other consumers of care. We should easily gather support from these groups since they are the very ones that enjoy the most benefit from the prevention-oriented care at which family physicians excel. Slots that will not produce a medical home type of product should not be funded. Other than perhaps pediatrics, psychiatry, or general surgery, evidence is lacking that supports a need for any increase in slots for subspecialty training.

Fixing our system depends upon providing continuous, longitudinal, comprehensive, coordinated, first-contact care to optimize health and to minimize the onset and effects of chronic disease. Who could argue against true primary care being the source? The current payment structure does not allow it. AFMRD Board of Directors advocacy efforts are exploring payment-for-care coordination so that office visits for these patients can contain all necessary elements. MedPAC recognizes that GME should produce doctors who function efficiently in the realms of evidencebased medicine, team-based care, care coordination, and shared decision making. Family medicine, leading the way in competency-based education, develops the skills and perspectives required to bring this about.

AFMRD's new strategic plan has advocacy as 1 of its 4 core items. Finance reform is a key component that hopefully will lead to enhanced student interest in family medicine. If achieved, that would be a loud sonic boom for the benefit of the health of all Americans!

Stoney Abercrombie, $M D_{i}$ Ed Evans, $M D_{i}$ Joseph W. Gravel Jr, MD, Karen L. Hall, MDi Grant Hoekzema, MD, Stanley Kozakowski, MD; Michael F. Mazzone, MD, Benjamin N. Scbneider, MD; Todd Shaffer, MD, Martin Wieschbaus, MD

\section{References}

1. Valderas, JM, Starfield B, Forrest CB, Sibbald B, Martin R. Ambulatory care provided by office-based specialist in the United States. Ann Fam Med. 2009;7(2):104-111. 